\title{
MEASURING CONSUMER INNOVATIVENESS: IDENTIFYING INNOVATORS AMONG CONSUMERS OF MODERN TECHNOLOGIES
}

\section{Filová, J.}

The methods currently used in innovation marketing research are focused on the late phases of the innovation process and are usually methodologically complex. This limits their practical impact. The presented work aims to create a simple self-report scale applicable in the initial and late phases of the innovation process, highly modular and suitable for a wide range of research. The main battery of questions was inspired by the adopter categorization by Rogers. The questions determine both (1) general characteristics of innovation adopters and (2) their relationship to a specific innovation. The scale was tested during robust longitudinal online research, thematically focused on users of modern technologies. A representative sample of 4,000 Internet users in the Czech Republic took part in the survey from 2013 to 2015. The result is a new self-report scale measuring consumer innovativeness applicable for prototyping, strategic decisions and effective communication of innovations to consumers.

Keywords: Adopter categorization; online research; consumer innovativeness; measurement of innovativeness; self-report scale.

JEL classification: M31, 032.

\section{Introduction}

Since the first publication on the concept of diffusion of innovations (Rogers, 1962), Big Data, cloud, mobile Internet, Internet of Things (IoT), or Internet of Everything (IoE) have had a significant impact on the world. These technologies have radically transformed many industrial sectors. In the last fifty years, the technological development has been accelerating according to Moore's Law, speeding up supply chains and increasing the requirements of companies for research and marketing innovations. New technological mega trends and trends have increasingly penetrated into the world of ordinary consumers and have influenced their behavior. Investigating these processes creates new challenges in the field of marketing research.

According to Rogers, "diffusion [of innovations] is a process in which an innovation is communicated through certain channels over time among the members of a social system. It is a special type of communication, in that the messages are concerned with new ideas." (Rogers, 2003, p. 5). The concept of the diffusion of innovations, together with Rogers' categorization of five ideal types of innovation adopters (innovators, early adopters, early majority, late majority, and laggards) (Rogers, 2003, p. 279-285), have quickly spread from academia to publications intended primarily for managers. In these publications, one cannot overlook the famous curve of adopter categorization (Figure 1). Most marketers and innovators probably know this curve from the book "Crossing the Chasm" by Moore (2014). 
Figure 1 | Rogers' Adopter Categorization on the Basis of Innovativeness

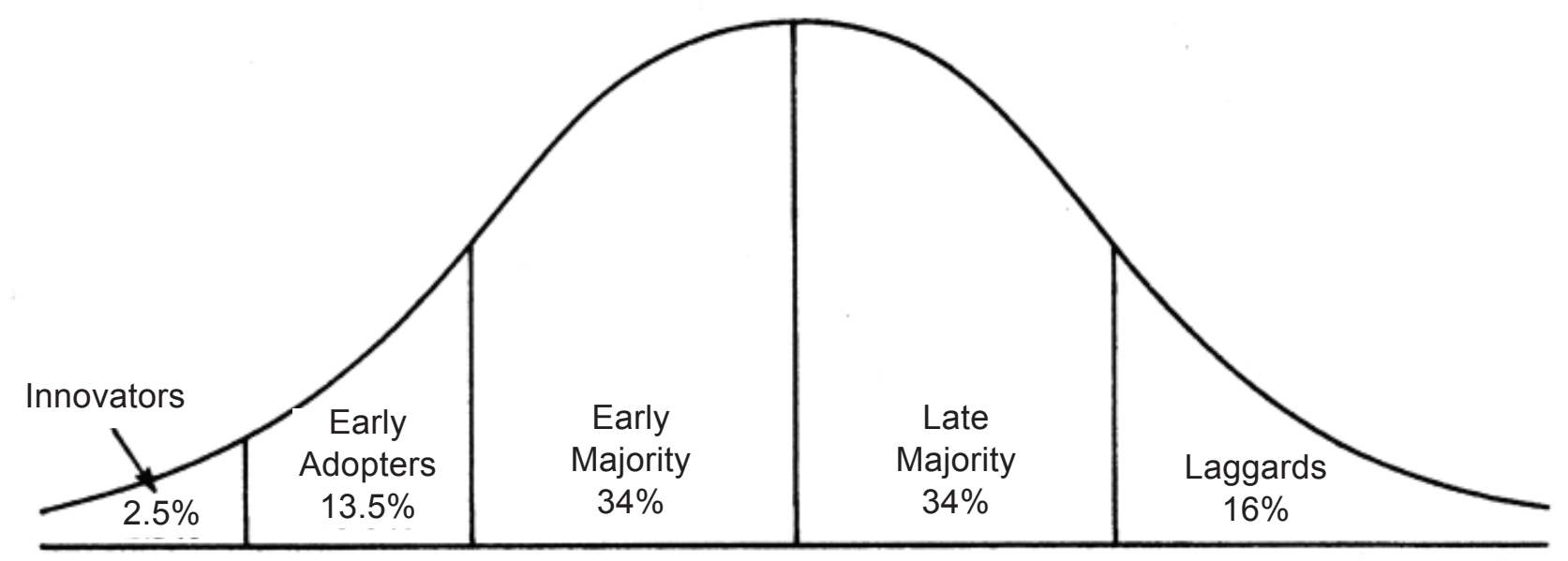

Source: Rogers (2003), p. 281.

Rogers was aware that adopter categorization is based on his observations that might not be exclusive (Rogers, 2003, p. 282). Since the first publication of Rogers' work in 1962, his work has inspired other scientists and marketers, especially in the United States. It became a challenge for exploration and development of diffusion and adoption models and scales, that seek to uncover patterns of diffusion of novelties (ideas, processes, information, products) among consumers.

Strategic marketing of innovations uses diffusion models in the last phase of the innovation process, i.e. in implementing and promoting innovations (Trommsdorff and Steinhoff, 2007). If the marketing communication aims at consumers that are at the right end of the adopter categorization curve (late majority and laggards), the result is a direct and rapid descent into the innovation chasm. Equally ineffective and useless is creating innovations without a sufficient knowledge about the consumers (especially those that are open to innovations, such as innovators and early adopters).

Let's assume that the marketing department of a technological company wants to reliably test a prototype of a new smart phone (or communicate information about it) and decides to use innovators. Innovators are obsessed with trying a new product or a service (Rogers, 2003, p. 282). They do not hesitate to go beyond the standard local network of contacts and information sources. Innovators play a very important role in the diffusion of innovations - they are the so-called gatekeepers (Moore, 2014, p. 39) that bring new ideas and innovations to the social system.

For successful deployment of an innovative product, the abovementioned marketing department needs to identify innovators (1) for research and development purposes (the initial phase of innovation process) and (2) for effective marketing communication of innovations. The commonly used methods to identify these innovative consumers are: personal recommendations, expert evaluation (e.g. Internet bloggers or Facebook users focused on new technologies with a broad audience), quota sampling from a company's database or from panel survey provided by a research agency. However, these approaches suffer from several drawbacks. For example, recommendations are subjective and introduce sample heterogeneity. Moreover, selection criteria are often 
based on the ownership of a particular technology that does not necessarily correlate with innovativeness. Therefore the marketing department still does not know whether (and to what extent) users of these technologies are innovative, i.e. suitable for testing of a prototype or helpful in marketing communication about new technology. This hypothetical case demonstrates the need for quantitative, accurate and widely applicable methods to confidently identify innovators suitable for early phases of the innovation process. Ideally, such methods should be simple in order to be easily adopted by large companies, as well as small companies and start-ups with limited marketing budgets. Simultaneously, these methods should be highly flexible to allow tailoring to a particular product or a communication channel.

This work aims to overcome the abovementioned limitations of previously described scales and develop an objective method to identify innovative consumers regardless of the nature of the innovative product that is tested or marketed. The two major goals are: (1) develop a self-report scale that meets the requirements for simplicity and flexibility, and (2) demonstrate its practical applicability on a particular example: users of modern technologies. The hypothesis tested in this work is:

H1: A self-report scale created according to adopter categorization developed by Rogers can be used to identify innovators.

\section{Methodology}

According to Rogers, the three most commonly used research methods for measuring opinion leadership and network links are: the sociometric method, informants' ratings and observation (Rogers, 2003, p. 308-312). Thematically they fit to Rogers' era (1931 - 2004): they are focused on social problems, such as limiting the spread of HIV infection, prevention of cancer, etc. Rogers also noticed the increasing importance of the Internet, although at the end of his life (2004) it was not as widespread as it is today. He acknowledged the Internet's mass media and interpersonal roles and also the fact that the study of the influence of the Internet on the diffusion of innovation had just begun. Goldsmith and Hofacker (1991) used a fourth method of measuring opinion leadership: a self-designating (self-report) method. In this method, each respondent is asked a series of questions to determine the degree to which he/she perceives himself/herself to be an opinion leader. Self-report techniques allow one to measure innovativeness more systematically, generally and enable researchers to predict innovativeness (Hurt, Joseph and Cook, 1977, p. 59). Goldsmith and Hofacker built on the global innovativeness scale by Hurt, Joseph and Cook and created the DSI (Domain Specific Innovativeness) scale that consists of six relatively long statements (Goldsmith and Hofacker, 1991). The major improvement of DSI compared to the global innovativeness scale is that the direction of items is not negatively worded. However, the practical use of DSI in marketing innovations encountered two main problems. Firstly, some of the statements are not suitable for research on radical innovation and very new products. The statements cannot determine whether the consumer actually has the knowledge and experience with the particular innovation (Goldsmith and Hofacker, 1991, p. 219). Secondly, the statements are too complex and try to determine several variables at once. The latter is a common characteristic of many other scales used for measuring of consumer innovativeness in the field of modern technologies (Chau and Hui, 1998, Hirunyawipada and Paswan, 2006). 
However, from a methodological point of view such an approach could be considered as incorrect (Bradburn, 2004, p. 36-37).

Another scale often used by specialists in market research is the six-item market maven scale by Feick and Price that is focused on identification of "individuals who have information about many kinds of products, places to shop, and other facets of marketing" (Feick and Price, 1987, p. 85). This scale is suitable for the latest phase of the innovation process - identification of opinion leaders that could motivate other consumers to purchase new products. However, the scale cannot be used for identification of innovators for early phases $-\mathrm{R} \& \mathrm{D}$ and prototyping. Moreover, it disregards the existence of the so-called quiet leaders described by Susan Cain (Cain, 2012). An open question is what role the market maven scale will play in the age of online savings portals, shopping guides and price comparators, big data and algorithmic economy. With the help of smart electronic devices and advanced machine learning, it is currently possible to monitor the consumer and model his/her shopping behavior in real time (including market maven's behavior). By using state-of-the-art technologies (HW and SW), analytical firms can easily access key information about the buying and communication process.

The self-report scale reported in this work was created with focus on simplicity of the questions to be easily understandable to the respondents. The individual questions are organized in a modular fashion into four batteries. The first battery reflects the adopter categorization by Rogers and measures innovativeness in relation with a specific product line. The second and third batteries determine the usage of specific products and communication channels, respectively. Finally, the fourth battery quantifies personal characteristics (traits) that are commonly associated with innovators.

\section{Data Collection}

With regard to my professional experience and to the research topic (users of modern technologies and of the Internet), I chose a modern research method: Computer-assisted web interviewing (CAWI). The data were gathered from a custom online panel with over 36,000 panel members (Data Collect, 2011). An online access panel for market and public opinion research provides a representative sample of Internet users. The composition of the panel corresponds to the structure of active Internet users in the Czech Republic. The structure of the panel is based on representative off-line surveys provided by the Czech Statistical Office and NetMonitor (audience measurement of the Czech Internet by The Association for Internet Progress, SPIR). The major tracked attributes are gender, age, education, region and population size of residence.

Data were collected quarterly from April 2013 to January 2015. The respondents were selected using quota sampling. The size of the sample was constantly 500 respondents. With eight quarterly measurements, I surveyed eight representative quota samples. The structure of the sample corresponded to the population of active Internet users in the Czech Republic according to gender, age (15+ years) and region. An online questionnaire was programmed in flexible and robust research software. Each respondent could see only one question at a time (with possible answers) and the order of the questions was the same for all respondents. 


\section{Experimental work}

The experimental part consisted of the work with data collection techniques and research methods, and creating and testing my own batteries of questions. As mentioned above, my research was focused on the method of self-designation (self-report). I developed an online questionnaire with four batteries of question. The main criteria for creating surveys questions were: methodological correctness, homogeneity (questions focused on the same topic), simplicity and comprehensibility. These criteria are prerequisites for practical application in R\&D and marketing of innovations that require efficient, fast and flexible solutions.

The first main topic was respondents' self-identified technology leadership. To explore this phenomenon, I used my own scale as the first battery of questions (Q1). These questions correspond to the adopter categorization by Rogers (2003, p. 287-299) and thematically focus on modern technologies. In the battery Q1, the respondents answered the question "What is your relationship to technological innovations?" with six statements in a four-item scale (strongly agree, somewhat agree, somewhat disagree, strongly disagree):

(Q1_1) I like to pass information about technological innovations to others.

(Q1_2) I am courageous and I want to be the first to test technological innovations.

(Q1_3) I adopt technological innovations quickly.

(Q1_4) I like to follow others (friends, colleagues, etc.) in adopting technological innovations.

(Q1_5) I start to use technological innovations after they are used by most of my friends, colleagues, etc.

(Q1_6) I do not like using technological innovation.

The other two batteries of questions (Q2, Q3) were focused on the use of modern technologies and social media. The battery Q2 determined the frequency of usage of 19 different technologies, ranging from radio, television, desktop computer without Internet access, to smartphone with Internet access. The battery Q3 determined the frequency of usage of eight social media, including Facebook, Twitter, Google Plus, LinkedIn, YouTube, and others. Respondents answered both batteries (Q2, Q3) in a six-item scale (every day, several times a week, once or twice a week, once or twice a month, less than once a month, never).

The second main topic was respondents' self-identified personality traits. To explore this phenomenon, I used my own scale as the fourth battery of questions (Q4) that was inspired by personality-strength scale by Noelle-Neumann (Noelle-Neumann, 2002, p. 97). I simplified the original battery of Noelle-Neumann to make it understandable by the widest range of respondents, and added a question about intuition (Q4_8), a personality trait commonly associated with innovations. The variable of the last question in this battery (Q4_11) is related to the first question of the first battery (Q1_1). The battery Q4 was intentionally placed as the last, in order to eliminate the memory footprint and to gain responses regardless of the answers from the battery Q1. I also replaced the two-item scale (yes, no) used by Noelle-Neumann with a four-item scale (strongly agree, somewhat agree, somewhat disagree, strongly disagree) to make it compatible with the first battery. The respondents were asked the question: "Which of the following terms describes you 
the best?" Each respondent had to identify himself/herself in the 11 following personality traits: success, self-confidence, responsibility, proactivity, speaking skills, leadership, self-assertion, using intuition, being ahead of the others, being different from the others and willingness to give advice.

\section{Data Analysis}

With respect to the size of the data file of the quarterly survey $(n=500)$ and in order to maximize robustness, I used a simple statistical methodology: Spearman's rank correlation coefficient and CHAID, statistically significant at the $p \leq 0.01$ level. The results of the eight quarterly surveys were averaged (Tables 1 - 3). Each value in the tables represents an average of the absolute values of statistically significant (not all) interactions that the given variable had with the examined battery of questions. In the CHAID analysis, the variables were assigned interaction points 1 or 0.5 . The most important variable (first in the tree for a given question) was assigned 1 point; variables in a later tree branch were assigned 0.5 point; if a variable appeared in all branches based on the first variable, it was assigned 1 point; in all other cases the variable was assigned 0 points. For each interaction between variables (e.g. Q1 vs. Q2), the interaction points were summed. The resulting sum was averaged over all eight measurements (Tables 1 - 3).

To identify innovators, data files of the partial surveys were grouped in two files $(\mathrm{R} 1$ - R4) and (R5 - R8) of equal size $(\mathrm{n}=2,000)$. The two files contained data of consecutive measurements (April 2013 - January 2014, April 2014 - January 2015). For this analysis, I used Pearson's chi square test (goodness of fit), statistically highly significant at the $\mathrm{p} \leq 0.001$ level. For the calculations I used PASW Statistics (SPSS 18) and MS Excel software.

\section{Results: Innovativeness vs. Use of Modern Technologies}

The analysis confirms the relationship between innovativeness and the use of modern technologies. The variable "smartphone with Internet access" repeatedly appeared as a stable variable in relation to the whole battery Q1. It consistently received the maximum value of the Spearman's correlation coefficient in the questions addressed to "innovators" (Q1_2) and "early adopters" (Q1_3). It also showed the strongest interaction between variables in CHAID analysis in all measurements (R1 - R8). During the two years of measurements, a constant decline was observed for the variables "tablet without Internet access". Minimum interactions were found for the variable "desktop computer without Internet access" with repeatedly negative values of Spearman's correlation coefficient for questions addressed to "innovators" (Q1_2) and "early adopters" (Q1_3). 
Table 1 | Relationship between innovativeness (Q1) and the use of modern technologies (Q2)

\begin{tabular}{|c|c|c|c|}
\hline $\begin{array}{l}\text { Modern technology } \\
\text { (question variables } \\
\text { Q2) }\end{array}$ & $\begin{array}{c}\text { The average number of } \\
\text { significant correlations } \\
\text { between } Q 1 \text { vs. Q2 } \\
\text { of all measurements } \\
(\mathrm{N}=4,000)\end{array}$ & $\begin{array}{l}\text { The average of the } \\
\text { absolute value of the } \\
\text { Spearman's correlation } \\
\text { coefficients Q1 vs. Q2 } \\
\text { of all measurements } \\
(\mathrm{N}=4,000)\end{array}$ & $\begin{array}{l}\text { The average number } \\
\text { of points from CHAID } \\
\text { Q1 in position of } \\
\text { explanatory variables } \\
\text { of all measurements } \\
(\mathrm{N}=4,000)\end{array}$ \\
\hline $\begin{array}{l}\text { Mobile phone } \\
\text { without Internet } \\
\text { access }\end{array}$ & 4.3 & 0.169 & 0.3 \\
\hline $\begin{array}{l}\text { Mobile phone with } \\
\text { Internet access }\end{array}$ & 0.9 & 0.099 & 0.2 \\
\hline $\begin{array}{l}\text { Smartphone } \\
\text { without Internet } \\
\text { access }\end{array}$ & 3.0 & 0.129 & 0.2 \\
\hline $\begin{array}{l}\text { Smartphone with } \\
\text { Internet access }\end{array}$ & 5.9 & 0.271 & 4.7 \\
\hline $\begin{array}{l}\text { Desktop computer } \\
\text { without Internet } \\
\text { access }\end{array}$ & 0.6 & 0.066 & 0.2 \\
\hline $\begin{array}{l}\text { Desktop computer } \\
\text { with Internet access }\end{array}$ & 0.1 & 0.015 & 0.0 \\
\hline $\begin{array}{l}\text { Laptop without } \\
\text { Internet access }\end{array}$ & 1.1 & 0.070 & 0.0 \\
\hline $\begin{array}{l}\text { Laptop with } \\
\text { Internet access }\end{array}$ & 3.1 & 0.136 & 0.2 \\
\hline $\begin{array}{l}\text { Tablet without } \\
\text { Internet access }\end{array}$ & 2.6 & 0.153 & 0.1 \\
\hline $\begin{array}{l}\text { Tablet with Internet } \\
\text { access }\end{array}$ & 4.9 & 0.206 & 1.0 \\
\hline E-book reader & 4.5 & 0.172 & 0.3 \\
\hline Digital camera & 3.6 & 0.150 & 0.1 \\
\hline $\begin{array}{l}\text { Digital video } \\
\text { camera }\end{array}$ & 3.9 & 0.192 & 0.4 \\
\hline GPS for cars & 5.1 & 0.211 & 1.3 \\
\hline Gaming console & 3.5 & 0.170 & 0.1 \\
\hline Home theater & 4.3 & 0.205 & 0.9 \\
\hline TV & 0.5 & 0.080 & 0.4 \\
\hline MP3 player & 3.5 & 0.147 & 0.8 \\
\hline Radio & 0.1 & 0.020 & 0.1 \\
\hline
\end{tabular}

Source: Author's own research 


\section{Results: Innovativeness vs. Use of Social Media}

The analysis confirmed the relationship between innovativeness and the variable "YouTube" (the largest global Internet page for sharing videos). In relation to the battery Q1, the variable "YouTube" appeared stable and showed the highest number of interaction points between variables in CHAID analysis. This social medium also showed almost invariably negative values of Spearman's correlation coefficient among the questions addressed to "late majority" (Q1_5) and "laggards" (Q1_6). Surprisingly, the least interactions between innovativeness and use of social media were found for the variable "Facebook".

Table 2 | Relationship between innovativeness (Q1) and the use of social media (Q3)

\begin{tabular}{|l|c|c|c|}
\hline $\begin{array}{l}\text { Social media } \\
\text { (question } \\
\text { variables Q3) }\end{array}$ & $\begin{array}{c}\text { The average number of } \\
\text { significant correlations } \\
\text { between Q1 vs. Q3 } \\
\text { of all measurements } \\
\text { (N=4,000) }\end{array}$ & $\begin{array}{c}\text { The average of the } \\
\text { absolute value of the } \\
\text { Spearman's correlation } \\
\text { coefficients Q1 vs. Q3 } \\
\text { of all measurements } \\
\text { (N=4,000) }\end{array}$ & $\begin{array}{c}\text { The average number } \\
\text { of points from CHAID } \\
\text { Q1 in position of } \\
\text { explanatory variables } \\
\text { of all measurements } \\
\text { (N=4,000) }\end{array}$ \\
\hline Facebook & 1.4 & 0.075 & 0.3 \\
\hline Twitter & 4.4 & 0.194 & 1.4 \\
\hline Google Plus & 4.5 & 0.180 & 1.3 \\
\hline LinkedIn & 3.0 & 0.166 & 0.2 \\
\hline YouTube & 5.0 & 0.210 & 2.6 \\
\hline Skype & 3.0 & 0.164 & 1.2 \\
\hline Pinterest & 1.9 & 0.106 & 0.0 \\
\hline Instagram & 3.1 & 0.153 & 0.4 \\
\hline
\end{tabular}

Source: Author's own research

\section{Results: Innovativeness vs. Personality Traits}

The analysis confirmed the relationship between innovativeness and measured personality traits. "Being ahead of others" repeatedly appeared as a stable variable in relation to the whole battery Q1. It consistently received the maximum value of the Spearman's correlation coefficient among the questions addressed to "innovators" (Q1_2) and "early adopters" (Q1_3). It also showed the strongest interaction between variables in CHAID analysis in all surveys (R1 - R8). Other long-term important variables were "self-confidence", "leadership", "self-assertion" and "willingness to give advice." The strongest interactions were found for variables "being ahead of the others" and "proactivity". Surprisingly, no significant relationship was found between innovativeness and "using intuition." The variables "speaking skills" and "responsibility" showed minimum of interactions. 
Table 3 | Relationship between innovativeness (Q1) and personal traits (Q4)

\begin{tabular}{|l|c|c|c|}
\hline $\begin{array}{l}\text { Personal } \\
\text { characteristics } \\
\text { (question variables } \\
\text { Q4) }\end{array}$ & $\begin{array}{c}\text { The average number } \\
\text { of significant } \\
\text { correlations } \\
\text { between Q1 vs. Q4 } \\
\text { of all measurements } \\
\text { (N=4,000) }\end{array}$ & $\begin{array}{c}\text { The average } \\
\text { of the absolute value } \\
\text { of the Spearman's } \\
\text { correlation } \\
\text { coefficients Q1 vs. Q4 } \\
\text { of all measurements } \\
\text { (N=4,000) }\end{array}$ & $\begin{array}{c}\text { The average number } \\
\text { of points from CHAID } \\
\text { Q1 in position of } \\
\text { explanatory variables } \\
\text { of all measurements } \\
\text { (N=4,000) }\end{array}$ \\
\hline Success & 4.8 & 0.214 & 0.6 \\
\hline Self-confidence & 5.0 & 0.211 & 0.4 \\
\hline Responsibility & 2.1 & 0.127 & 0.1 \\
\hline Proactivity & 4.9 & 0.242 & 0.1 \\
\hline Speaking skills & 3.5 & 0.167 & 0.5 \\
\hline Leadership & 5.3 & 0.215 & 0.8 \\
\hline Self-assertion & 5.3 & 0.222 & 0.4 \\
\hline Using intuition & 3.9 & 0.178 & 4.0 \\
\hline $\begin{array}{l}\text { Being ahead of the } \\
\text { others }\end{array}$ & 5.6 & 0.287 & 0.3 \\
\hline $\begin{array}{l}\text { Being different from } \\
\text { the others }\end{array}$ & 4.3 & 0.169 & \\
\hline $\begin{array}{l}\text { Willingness to give } \\
\text { advice }\end{array}$ & 4.8 & 0.173 & \\
\hline
\end{tabular}

Source: Author's own research

\section{Identification of Innovators}

In the beginning of this research paper, I presented a problem of a hypothetical marketing department of a technological company that decided to use innovators for testing a prototype of a new smartphone. To identify these innovators among the respondents of my research, I used a self-report scale measuring consumer innovativeness (Q1). The innovators were identified in files (R1 - R4) and (R5 - R8) as the respondents that answered the questions Q1_2 to Q1_4 with "strongly agree", and simultaneously answered the questions Q1_5 and Q1_6 with "strongly disagree". Based on the above criteria, a total of 28 respondents $(1.4 \%$ of the total) were identified in the first group (R1 - R4) and 37 respondents $(1.9 \%$ of the total) in the second group (R5 - R8). Rogers assumed that the percentage of innovators in the population is small. In my research, the respondents were online panel members, i.e. active Internet users who use various (more or less) innovative technologies to connect to the Internet. Based on this, we could assume that the percentage of technological innovators within this group will be higher than $2.5 \%$ estimated by Rogers (Rogers, 2003, p. 281). The percentage of innovators found in my research $(1.4 \%$ and $1.9 \%)$ can be considered as adequate for further analysis for the 
following reasons. Firstly, it is important to highlight the difference between modern technology innovativeness and the use of modern technologies. They are two different variables. Therefore, these variables were measured separately. Secondly, it is important to perform the investigation methodically correctly, including the correct formulation of questions. The combination of these two factors allowed the elimination of bias and non-reliable data.

The results of this analysis showed that the innovators used more frequently modern technologies, such as a "smartphone with Internet access" and "laptop with Internet access". Innovators were also very active on Facebook, but this was true for most respondents. The second most frequently used social medium by innovators was YouTube. There was also a noticeable increase in the use of YouTube by innovators during the measurement period (R1 - R8). The results correlate with the finding of another survey for this time period provided by Google Czech Republic (Google, 2014) that revealed an overall increase in YouTube usage among Czech Internet users.

Within the studied personality traits, the most significant characteristics of innovators were "willingness to give advice", "responsibility" and "proactivity". These characteristics can be considered equivalent to those suggested for innovators by Rogers (2003, p. 282-283). The findings in this paper confirm the correctness of the hypothesis that the self-report scale created according to the adopter categorization developed by Rogers can be used to identify innovators.

In practice, this means that the marketing department of the technological company could approach selected respondents to test a prototype of a new smartphone. According to the findings in this paper, they would optimally use YouTube in combination with Facebook as the communication channel.

Table 4 | Modern technologies and social media most used by innovators

\begin{tabular}{|c|c|c|c|}
\hline & Frequency of use & $\begin{array}{l}\text { Relative frequency } \\
\text { of the most frequent } \\
\text { responses by } \\
\text { innovators ( } n=28 \text { ) in the } \\
\text { measurement (R1 - R4) }\end{array}$ & $\begin{array}{c}\text { Relative frequency } \\
\text { of the most frequent } \\
\text { responses by } \\
\text { innovators ( } n=37 \text { ) in the } \\
\text { measurement ( } R 5 \text { - R8) }\end{array}$ \\
\hline \multirow{2}{*}{$\begin{array}{l}\text { Smartphone } \\
\text { with Internet } \\
\text { access }\end{array}$} & Every day & $79 \%$ & $83 \%$ \\
\hline & Never & $11 \%$ & $8 \%$ \\
\hline \multirow{2}{*}{$\begin{array}{l}\text { Laptop with } \\
\text { Internet access }\end{array}$} & Every day & $75 \%$ & $76 \%$ \\
\hline & Several times a week & $7 \%$ & $11 \%$ \\
\hline \multirow{2}{*}{ Facebook } & Every day & $54 \%$ & $32 \%$ \\
\hline & Never & $14 \%$ & $19 \%$ \\
\hline \multirow{2}{*}{ YouTube } & Every day & $25 \%$ & $54 \%$ \\
\hline & Several times a week & $39 \%$ & $24 \%$ \\
\hline
\end{tabular}

Source: Author's own research 


\begin{tabular}{|l|l|c|c|}
\hline & $\begin{array}{c}\text { Rate of self- } \\
\text { determination }\end{array}$ & $\begin{array}{c}\text { Relative frequency of the } \\
\text { most frequent responses } \\
\text { by innovators (n=28) in the } \\
\text { measurement (R1 - R4) }\end{array}$ & $\begin{array}{c}\text { Relative frequency of the } \\
\text { most frequent responses } \\
\text { by innovators (n=37) in } \\
\text { the measurement (R5 - R8) }\end{array}$ \\
\hline \multirow{2}{*}{$\begin{array}{l}\text { Willingness to } \\
\text { give advice }\end{array}$} & Completely agree & $64 \%$ & $62 \%$ \\
\cline { 2 - 4 } & Somewhat agree & $36 \%$ & $38 \%$ \\
\hline \multirow{2}{*}{ Responsibility } & Completely agree & $54 \%$ & $57 \%$ \\
\cline { 2 - 4 } & Somewhat agree & $39 \%$ & $41 \%$ \\
\hline \multirow{2}{*}{ Proactivity } & Completely agree & $50 \%$ & $54 \%$ \\
\cline { 2 - 4 } & Somewhat agree & $46 \%$ & $43 \%$ \\
\hline
\end{tabular}

Source: Author's own research

\section{Conclusion}

This paper presents a new self-report scale for measuring consumer innovativeness based on the adopter categorization by Rogers. The hypothesis that such a scale can be used to identify innovators was confirmed on a specific case of users of modern technologies. However, the modular construction of the scale makes it easily adaptable to other fields and products. Importantly, the new scale allows measuring innovativeness that is not innovation-specific, and thus can be applied (not only) in the early phase of the innovation process (planning product innovations and strategic decisions). The simplicity and flexibility of the scale offer high potential for its wide adoption by companies of various sizes, including start-ups with limited budgets. In the near future, marketing research will face harsh competition from modern technologies that allow automated monitoring and predicting of consumer behavior in real time. Despite these technological advances, scales that allow identification of innovators without prior experience with the particular innovation will still likely play an important role for diffusion of radical innovations.

\section{References}

Bradburn, N. M. (2004). Asking Questions (Rev. ed.) San Francisco: Jossey-Bass.

Cain, S. (2012). Quiet: The Power of Introverts in a World That Can't Stop Talking. New York: Crown (1900).

Data Collect (2011). Panel book. Retrieved October 31, 2015, http://www.datacollect.cz/ wp-content/uploads/2014/06/datacollect_panelbook.pdf.

Feick, L. F., \& Price, L. L. (1987). The Market Maven: A Diffuser of Marketplace Information. Journal of Marketing, 51(1), 83-97.

Goldsmith, R. E. (1991). The Validity Of A Scale To Measure Global Innovativeness. Journal of Applied Business Research, 7(2), 89-97.

Goldsmith, R. E., \& Hofacker, C. (1991). Measuring Consumer Innovativeness. Journal of the Academy of Marketing Science, 19(3), 209-221. 
Google Czech Republic (2014). YouTube v ČR 2014 Profiling studie. Retrieved October 31, 2015 from http://www.provasbyznys.cz/download/cms/files/YouTube\%20profiling\%202014.pdf.

Hirunyawipada, T., \& Paswan, A. K. (2006). Consumer innovativeness and perceived risk: implications for high technology product adoption. Journal of Consumer Marketing, 23(4), 182-198.

Hurt, H. Y., Joseph, K., \& Cook, C. D. (1977). Scales for the Measurement of Innovativeness. Human Communication Research, 4(1), 58-65.

Chau, P. Y. K., \& Hui, K. L. (1998). Identifying early adopters of new IT products: a case of Windows 95. Information and Management, 33(5), 225-30.

Moore, G. A. (2014). Crossing the Chasm (3rd ed.) New York: Harper Business.

Noelle-Neumann, E. (2002). Die soziale Natur des Menschen. Beiträge zur empirischen Kommunikationsformschung. Freiburg/München: Verlag Karl Alber.

Rogers, E. M. (1962). Diffusion of Innovations (11 th ed.) New York: Free Press.

Rogers, E. M. (2003). Diffusion of Innovations (5th ed.) New York: Free Press.

Trommsdorff, V., \& Steinhoff, F. (2007). Innovationsmarketing. München: Franz Vahlen.

\section{Author}

\section{Bc. Jana Filová, MSc}

Consultant, External Ph.D. Student

Faculty of Business Administration, University of Economics, Prague

nám. W. Churchilla 4, 13067 Prague 3, ČR

janafilova.com@gmail.com 